\title{
Technophobia as emerging risk factor in aging: Investigation on computer anxiety dimension
}

\author{
Dina Di Giacomo, Federica Guerra, Enrico Perilli, Jessica Ranieri \\ Department of Life, Health and Environmental Sciences, University of L'Aquila, Italy
}

\begin{abstract}
Digital innovation changed the daily living impacting Quality of Life of individuals. Our study was focused on adult and elder behavioural approach to the technology. Out study aimed to investigate the impact of technology use in not digital native in order to investigate the behavioural degree of adaptation. An observational study was conducted on adult and old subjects (age range 50-67 years) measuring computer anxiety and technology use ability variables identifying the indexes for technophobia risk in digital living. Not digital native subjects and more older ones appeared being influenced by technophobia features because of feeling themselves as inadequate in the management of technology. Oneway ANOVA and then Bonferroni's post-hoc analysis showed that non-autonomous $(\mathrm{p}<0.01)$, low-frequency $(\mathrm{p}<0.01)$, and feelingneed-for-help users $(p<0.01)$ had higher levels of computer anxiety. No significant effect was in gender distribution. Finally, social networking seems related better use of technology and
\end{abstract}

Correspondence: Federica Guerra, Department of Life, Health and Environmental Sciences, University of L'Aquila, P.le Tommasi 1, 67010 L'Aquila, Italy.

E-mail: federica.guerra@graduate.univaq.it

Key words: Digital skills, computer anxiety, adulthood, use of technology.

Contributions: Conceptualization, writing, review and editing, D.D.G; methodology EP and JR; formal analysis, FG; writing, original draft preparation, all authors.

Conflict of interest: The authors declare no potential conflict of interest.

Funding: None.

Availability of data and materials: All data and materials are available within the text.

Ethics approval and consent to participate: The study adhered to the Declaration of Helsinki (Declaration of Helsinki History Website, 2015).

Informed consent: Informed consent was obtained from each participant.

Received for publication: 5 April 2019.

Accepted for publication: 27 November 2019.

This work is licensed under a Creative Commons AttributionNonCommercial 4.0 International License (CC BY-NC 4.0).

C Copyright: the Author(s), 2020

Licensee PAGEPress, Italy

Health Psychology Research 2020; 8:8207

doi:10.4081/hpr.2020.8207 lower anxiety for digital solutions. Our findings highlight technophobia as a possible new risk factor for not digital native because it can affect their daily life through lower adherence to digital solutions; rather than aging successfully, they could develop fragile ageing. More, they seemed inadequate to use the digital solutions for better living in aging.

\section{Introduction}

Digital skills are vital now and more for future in order to exploit better innovative living. Human digitalization increased by digital education in young generation, less in adulthood (Bennet et al., 2010). More, technological advancement and personalized health information has to be boosted for better adherence of the users (Bianchi et al., 2020). Chau et al., (2019) highlighted technological solutions for healthcare could be managed fitting better the needs of individuals: Authors recommended to improve technical attributes mirroring the adaptation to the human emotions and cognition. In fact, scientific literature indicated that someone's may experience difficulties and frustration with technologies. Following that, researches are paying attention on negative and positive variables influencing the digital application by the users (Barnard et al., 2010; Garçon et al., 2016). While the benefits of computer learning and applications are abundant, on the negative side, the evidence is less investigated. Psychological implications of technologies is turning basic for the adaptive learning machine and artificial intelligence studies. External and internal variables of human can play fundamental role towards to better exploitations of digital innovations. Internal variables as well emotions, personality, anxiety, fair, depression or more cognitive abilities can affect the interaction human-machine making; the artificial intelligence studies figure out solutions for better interaction. Remains to be investigated how digital living isn't accessible to the individuals or not so easy to manage. Gilroy \& Desai (1986) defined the computer anxiety as the "concept-specific and covers a wide variety of situations in which people interact with computers" (p. 711). Then, Desay \& Richards (1998) evidenced as the late adoption of technology and related apps/services can influence negatively the digital performance in people who have misconceptions about technology or lack information technology literacy; individuals tend to show anxiety, depression. Usually, this fear is related to irrational fear of computers, robots, artificial intelligence, weapons, and other such things that seem advanced in scientific thought.

Frequently the non-tech-savvy older population faces a risk of lowered quality of life and chances of inclusion. The ability of older adults to use digital solutions and tools is a crucial issue, because low adaptation to the digital era is a barrier in daily living, reducing quality of life, independence, autonomy, and mental health; additionally, such tools could effectively enhance medical 
care in elderly individuals (Ha et al., 2011; Osiceanu, 2015).

Studies about the interaction adults and technologies are almost entirely conducted on the technical aspect of the devices working on products and services designed to improve quality of life for older people (Cesta et al., 2004; Poscia et al., 2015; Iancu \& Iancu, 2017). A further interesting topic is the impact of technology in the cognitive development in young generation (Bennet \& Maton, 2010; Li et al., 2013; Hsin et al., 2014; Wollscheid et al., 2016;) and improvement of cognitive ability in elderly in rehabilitation field (Di Giacomo et al., 2014; Hou et al., 2017).

Our study wanted to deal with the adherence to digital living by adults and olds investigating the emotional feeling in the technological using. Out point of view is the individuals in interaction with devices detecting the psychological aspects predictive of low adherence to modern living.

\section{Materials and Methods}

\section{Participants}

A total of 117 adults ( $n=64$ female, $n=53$ male) aged 50 and above were recruited from middle Italy living in a metropolitan area. The participants ranged from 50 to 67 years of age with a mean age of $69.43(\mathrm{SD}=6.01)$. Table 1 reports the demographic data of the sample. The inclusion criteria were as follows: a) aged 50-70 years, b) no sign of psychiatric or neurological diseases, and c) gave informed consent.

\section{Test}

The measurement was based on detection of demographics, technology use, and psychological traits.

The battery was composed of 2 questionnaires (Table 2). The first was an ad-hoc self-report collecting demographic (education, occupation, living area) and technology use data (frequency, typology of use, etc.). The second was the standardized test the "Short Computer Anxiety Scale."

\section{Technology Use Self-report (TUS)}

The TUS is an experimental self-report aimed to evaluate the confidence of technology use. The detection data about the use of technology in daily life and is articulated in 4 indexes: 1) self-perception of technology use index, 2) frequency of use index, 3) social use of technology index and 4) User index about digital autonomy. Cronbach's alpha for the scale was .71.

\section{Short Computer Anxiety Scale}

Short Computer Anxiety Scale (Lester et al., 2005 - SCAS). This is a brief measure of computer-related anxiety composed of 6 items (and Likert-type responses); it aimed to detect the confidence in using computers. Cronbach's alpha for the scale was .78 .

\section{Procedure}

Participation in the study was voluntary, and signed Informed Consent was mandatory. The recruitment was conducted in creative centres. Participants completed the self-reports over 20 minutes. Both enrolling and test applying were conducted by trained psychologists. Scoring was performed by independent clinical psychologists. The data were collected into a database elaborated by SPSS.

\section{Study design}

This was a cross-sectional, observational study of the adult population recruited in a medical laboratory.

\section{Statistical analysis}

Descriptive statistics, such as mean with standard deviation and frequencies with percentages, were used to examine the characteristics of the sample. The sample was categorized by indexes

Table 1. Demographic data of participants and their distribution in technology use indexes.

\begin{tabular}{lc} 
& N $(\%)$ \\
Gender & \\
Female & $64(54.7)$ \\
Male & $53(45.3)$ \\
Education & \\
$\quad$ Non-graduate & $16(13.7)$ \\
High school & $58(49.6)$ \\
Graduate & $43(36.8)$ \\
\hline Relationship Status & \\
Married/living with partner & $88(75.2)$ \\
Single & $12(10.3)$ \\
Divorced/widows & $17(14.5)$ \\
Occupation & \\
Unemployed & $7(6.0)$ \\
Employed & $69(59)$ \\
Retired & $37(31.6)$ \\
Housewife & $4(3.4)$ \\
\hline Use of Technology & \\
Autonomous & $84(71,8)$ \\
Non-autonomous & $33(28,2)$ \\
Use Frequency & \\
High frequency & $105(89.7)$ \\
Low frequency & $12(10.3)$ \\
\hline Social Use of Technology & \\
Social & $100(85.5)$ \\
Non-social & $17(14.5)$ \\
Self-perception of Technology Use & \\
Feeling confident & $105(89.7)$ \\
Feeling need for help & $12(10.3)$ \\
\hline &
\end{tabular}

Table 2. One-way analysis of variance comparing Short Computer Anxiety Scale and technology use indexes.

\begin{tabular}{lccc} 
& Mean (sd) & F & p \\
& & 4,8 & $0.03^{*}$ \\
$\begin{array}{l}\text { Use of Technology } \\
\quad \text { Autonomous }\end{array}$ & 12.5 & & \\
$\quad$ Non-autonomous & 19.1 & & \\
$\quad$ Use Frequency & & 8.5 & $0.005^{* *}$ \\
$\quad$ High frequency & 13.5 & & \\
$\quad$ Low frequency & 22.2 & & \\
\hline $\begin{array}{l}\text { Social Use of Technology } \\
\quad \text { Social }\end{array}$ & 14.3 & 0.85 & 0.35 \\
$\quad$ Non-social & 14.3 & & \\
$\quad \begin{array}{l}\text { Self-perception of Technology Use } \\
\quad \text { Confident }\end{array}$ & 13.3 & 16.6 & $0.000^{* * *}$ \\
$\quad$ Feeling need for help & 23.7 & & \\
\hline
\end{tabular}


of the TUS, and the differences between these categories were assessed with the MANOVA test for quantitative variables. When the results were statistically significant, Bonferroni's test was used for pairwise comparisons in the post-hoc analysis.

A P-value of $<0.05$ was the criterion for statistical significance. The data were processed using SPSS.

\section{Results}

Firstly, the MANOVA analysis comparing the age and gender on psychological tests evidenced no significant effect.

Then, we distributed participants in n. 4 Technology Use categories: by the Use of Technology n. 84 was categorized autonomous (and n. 36 not autonomous); by Use Frequency n. 105 high frequency (and n. 12 low frequency); by social Use of Technology n. 100 social (and n. 17 not-social); finally by Selfperception of technology use n. 105 feeling confident (and n. 12 feeling need for help).

The distribution of participants in Technology Use evidenced high frequency in positive approach to technology.

Then we operated an ANOVA analysis comparing the SCAS scores and indexes of the TUS test.

One-way ANOVA highlighted significant differences in Use of Technology $(F(1,2)=4,8 ; p<0.005)$, Use Frequency $(F(1,2)=8,5$; $\mathrm{p}<0.03)$, and Self-perception of technology use $(\mathrm{F}(1,2)=16.6$; $\mathrm{p}<0.001)$ indexes. Bonferroni's post-hoc analyses showed that notautonomous $(\mathrm{p}<0.01)$, low-frequency $(\mathrm{p}<0.01)$, and feeling-needfor-help users $(p<0.01)$ had higher levels of computer anxiety.

Sociodemographical data as education and occupation wasn't significant variables.

Then, using the median age value (58), we divided the sample into 2 subgroups by age: adult (age range 50-58) and senior (age range 60-68), and compared the SCAS scores using one-way ANOVA; no significant difference was found.

\section{Discussion and Conclusions}

Digital competence feeling in aging is the topic of present study. Particularly, we wanted to investigate the adulthood application in the daily digital solutions in order to highlight the weakness and strengthens. Following our preview study (Di Giacomo et al., 2019), findings confirmed the rule of self-perception in digital application in order to exploit digital living benefits. Our study evidenced as the low digital skills in adulthood isn't associated to gender, aging or education variables; the computer anxiety in adulthood is related to the self-perception of own ability to use the technology autonomously. Examining the computer anxiety adults and older people resulted mostly feeling adequate in the application of digital solutions. A small number of participants showed anxiety related to the use of digital tools and cannot able to exploit the its potential. Many researchers pay attention to the lifelong learning, to the digital empowerment in working and educational contexts, neglecting the emerging focus of digital needs: the no-net generations.

Adulthood and elderly are related to population is not digitally skilled, enlarging the gap between the young generation (native digital) and adults (divided into digital and non-digital adults and seniors). Our data are interesting: mostly people developed digital confidence with digital living, on contrary, someone's still feel negative emotions (for instance anxiety, fear do not be autonomous). Even not relevant part, who feels himself/herself inadequate in the technological application represents a societal challenge because his/her inclusivity in digital living is inadequate and likely affects own quality of life. As evidenced by Osiceanu (2015), digital living can impact negatively the daily life of adults and older and is emerging new emotional patterns related to the modern living; those could affect the wellness in adulthood in terms of adherence to digital health and reducing the chance to improve the quality of life applying Active Assisted Living (AAL, Cesta et al., 2007). Efforts could be to improve the technological solutions designed properly for healthy ageing, even more because people are living longer than before so the adult and old needs should be the priority of digital future providing new strategies to increase the aging well in digital world supporting the mental health and the wellness.

\section{References}

Barnard, Y., Bradley, M.D., Hodgson, F., \& Lloyd, A.D. (2013). Learning to use new technologies by older adults: perceived difficulties, experimentation behaviour and usability. Computers in Human Behavior, 29, 1715-1724.

Bennett, S., \& Maton, K. (2010). Beyond the 'digital natives' debate: towards a more nuanced understanding of students' technology experiences. Journal of Computer Assisted Learning, 26, 321331. doi: 10.1111/j.1365-2729.2 010.00 360.x

Bianchi S., Bernardi S., Perilli E., Cipollone C., Di Biasi J., Macchiarelli G. (2020) Evaluation of effectiveness of digital technologies during anatomy learning in nursing school. Applied Sciences, 10, n.2357.

Cesta, A., Cortellessa, G., Giuliani, M.V., Pecora, F., Scopelliti, M., Tiberio, L. (2007) Psychological Implications of Domestic Assistive Technology for the Elderly. Psychology, 5, 229-253.

Chau Chau, K. Y., Lam, M. H. S., Cheung, M. L., Tso, E. K. H., Flint, S. W., Broom, D. R., Tse, G., \& Lee, K. Y. (2019). Smart technology for healthcare: Exploring the antecedents of adoption intention of healthcare wearable technology. Health Psychology Research, 7(1). https://doi.org/10.4081/ hpr.2019.8099

Desai, M.S., \& Richards, T.C. (1998). Computer anxiety, training and education: A meta analysis. Journal of Information Systems Education, 9(1), 49-54.

Di Giacomo D., Palmiero M., \& Passafiume D., (2014). Cognitive abilities in the use of smart technology: difference in life span. International Journal of Technology Enhanced Learning, 5, 299-306.

Di Giacomo D., Ranieri J. D’Amico M., Guerra F., Passafiume D (2019) Psychological Barriers to Digital Living in Older Adults: Computer Anxiety as Predictive Mechanism for Technophobia. Behavioral Sciences. 2019 Sep 11;9(9) doi:10.3390/bs9090096.

European Commission (2017), Digital Scoreboard 2017. Available from: https://ec.europa.eu/digital-single-market/en/digitalscoreboard

Garçon, L., Khasnabis, C., Walker, L., Nakatani, Y., Lapitan, J., Borg, J., Ross, A., \& Velazquez Berumen, A., (2016). Medical and Assistive Health Technology: Meeting the Needs of Aging Populations. Gerontologist, 56, S293-S302.

Gilroy \& Desai (1986) Computer anxiety: sex, race and age. International Journal of Man-Machine Studies, 26, 711-719

Hou J., Wu Y., Harrell E. (2017) Reading on paer and screen 
among senior adults: cognitive map and technophobia. Frontiers in Psychology 8:2225. doi: 10.3389/ fpsyg.2017.02225

Hsin, C.T., Li, M.C., \& Tsai, C.C. (2014). The influence of young children's use of technology on their learning: a review. Journal of Educational Technology \& Society, 17, 85-99.

Iancu, I., \& Iancu, B., (2017). Elderly in the Digital Era. Theoretical Perspectives on Assistive Technologies. Technologies 5, 60 .

Li, L., Chen, G., \& Yang, S. (2013). Construction of cognitive maps to improve e-book reading and navigation. Computers \& Education, 60, 32-39.
Osiceanu, M.E., (2015). Psychological Implications of Modern Technologies: "Technofobia" versus "Technophilia". Procedia - Social and Behavioral Sciences 180, 1137-1144.

Poscia, A., Frisicale, E.M., Parente, P., La Milia, D.I., de Waure, C., \& Di Pietro, M.L., (2015). Study habits and technology use in Italian university students. Annali dell'Istituto Superiore di Sanità, 51, 126-129.

Wollscheid, S., Sjaastad, J., \& Tømte, C. (2016). The impact of digital devices vs. pen(cil) and paper on primary school students' writing skills - a research review. Computers \& Education, 95, 19-35. 